\title{
Improving Salinity Tolerance in Brassica (Brassica napus var. Bsa and Brassica campestris var. Toria) by Exogenous Application of Proline and Glycine Betaine
}

\author{
Ameer Khan ${ }^{a}$, Hira Fatima ${ }^{b}$, Abdul Ghani ${ }^{a}$, Muhammad Nadeem ${ }^{c}$, Abida Aziz $^{\text {, }}$, \\ Mujahid Hussain ${ }^{\mathrm{a} *}$ and Muhammad Ikram ${ }^{a}$ \\ ${ }^{a}$ Department of Botany, University of Sargodha, Sargodha, Pakistan \\ ${ }^{b}$ Department of Botany, The University of Lahore, Sargodha, Pakistan \\ ${ }^{c}$ Institute of Food Science and Nutrition, University of Sargodha, Sargodha, Pakistan
}

(received August 29, 2016; revised March 10, 2017; accepted March 14, 2017)

\begin{abstract}
The pot culture experiment was conducted to determine the influence of proline and glycine betaine on Brassica under saline conditions. Different salinity levels $(0,65,130 \mathrm{mM})$ were created according to the saturation percentage of the soil. Proline $(0,4,8 \mathrm{mM})$ and glycine betaine $(0,5,10 \mathrm{mM})$ were exogenously applied to find out their effects on growth and physiological changes produced in Brassica under salinity stress. Salinity stress reduced the growth of the plants and induced the physiological and biochemical changes. Different growth parameters of plants such as plant height, shoot, root fresh and dry weight was decreased with the increase of salinity stress. Salinity has also reduced the chlorophyll content, protein content and nitrate reductase activity of the Brassica. But the application of proline and glycine betaine was more effective to reduce the effect of salinity. Collected data from the present experiment indicated that adverse effects of salinity were counteracted by proline and glycine betaine. Overall, it was observed that exogenous application of both proline and glycine betaine has reduced the effect of salinity.
\end{abstract}

Keywords: Brassica napus, Brassica compestris, proline, glycine betaine

\section{Introduction}

Soil salinity along with a variety of environmental stresses is now a very serious problem all over the world due to its adverse effects on plant growth and physiology (Taie et al., 2013). Salt stress is a great challenge for agriculture. Yield of the crop is reduced because crops fail to cope with salinity stress (Aymen and Cherif, 2013). There is 22 million hectares arable land in Pakistan. About $24 \%$ of crops of Pakistan are grown on rainfed land, whose area is about 4.6 million hectares (Muhammad and Muhammad, 2007). All over the world $35 \%$ agricultural production has been decreased due to salinity. Salinity affects $7 \%$ of the world's entire land area (Chaum et al., 2012). Salinization of arable land is increasing day by day and it is expected that after 25 years $30 \%$ of the total land area will face the problem of salt stress (Latef and Chaoxing, 2014; Kapoor et al., 2013). Crop growth and productivity are decreased by soil salinity (Cominelli et al., 2013).

Plants protect themselves from injurious and destructive effects of salt stress by producing different compatible osmoprotectant metabolites such as proline and glycine

*Author for correspondence;

E-mail: mujahid.hussain7877@gmail.com betaine (Chelli-Chaabouni et al., 2010). These osmolytes gather in the plant and protect tissue and cellular membranes of the plant (Anjum et al., 2012). It has been reported that foliar spray of proline and glycine betaine is valuable for plants in mitigating salt induced injuries (Ahmad et al., 2012; Hoque et al., 2007).

Proline and glycine betaine are also source of carbon and nitrogen. They stabilize the structures of membranes. Proline metabolism has a main role in storage and transfer of energy (Gilberti et al., 2014). The effects of salinity stress can be decreased by foliar application of the osmolytes i.e. proline and glycine betaine. In the plants stress tolerance quality is enhanced by the application of foliar spray and it is also a beneficial plan (Ali and Ashraf, 2011).

Brassica species are present in family Cruciferae. Members of the family Cruciferae are known as mustard plants. The petals of the plants belonging to this family are in a cross manner i.e. four petals are cross shaped. Canola (Brassica napus and Brassica campestris L.) is an important oil seed crop, its world average is 1,820 $\mathrm{kg} / \mathrm{ha}$ (Chambo et al., 2014). 13\% of the world's demand of oil is obtained from canola. Oil content of canola seeds is $40 \%$ (Snowdon et al., 2007). The experiment 
was conducted to determine the effect of proline and glycine betain on brassica under saline conditions.

\section{Materials and Methods}

The pot culture experiment was conducted in Department of Botany, University of Sargodha, Sargodha Pakistan. Proline and glycine betaine were applied exogenously to improve salinity tolerance in plants. The experiment was laid out in completely randomized design (CRD) with three replications.

Physiological parameters. Chlorophyll content. Method proposed by Davies (1976) was used to compute the chlorophyll contents. The extraction from the $0.5 \mathrm{~cm}$ chopped leave pieces was done with $5 \mathrm{~mL}$ acetone $(80 \%)$ and kept at $10{ }^{\circ} \mathrm{C}$. The absorbance of the supernatant was measured at 645 and $663 \mathrm{~nm}$ on spectrophotometer. $\mathrm{Chl} \mathrm{a,} \mathrm{Chl} \mathrm{b} \mathrm{and} \mathrm{total} \mathrm{chlorophyll}$ were calculated by using the following formula:

$$
\begin{aligned}
& \text { Chl. } \mathrm{a}=[12.7(\text { OD } 663)-2.69(\text { OD } 645)] \times \mathrm{V} / 1000 \times \mathrm{W} \\
& \text { Chl. } \mathrm{b}=[22.9(\text { OD 645) }-4.68(\text { OD 663) }] \times \mathrm{V} / 1000 \times \mathrm{W} \\
& \text { Total Chl. }=[20.2(\mathrm{OD} 645)+8.02(\mathrm{OD} 663)] \times \mathrm{V} / 100 \times \mathrm{W} \\
& \mathrm{V}=\text { Volume of the extract } \\
& \mathrm{W}=\text { Weight of the sample }
\end{aligned}
$$

Total free amino acids. Method proposed by Hamilton and Van Slyke (1943) was used to compute the total free amino acids. Chopped segments of leaves were extracted with $0.2 \mathrm{M}$ phosphate buffer of $7.0 \mathrm{pH} .1 \mathrm{~mL}$ from extract, $10 \%$ pyridine and $2 \%$ ninhydrin solution were put in the test tube. Distilled water was used to make the volume upto $50 \mathrm{~mL}$. The optical density of this coloured solution was seen at $570 \mathrm{~nm}$ on spectrophotometer (Hitatchi, 220, Japan). A standard curve was made with Leucine and then calculation for free amino acids was done by this formula:

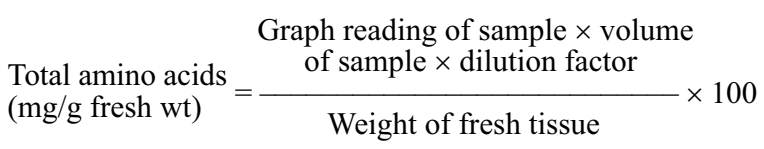

Nitrate reductase activity (NRA). Method proposed by Sym (1984) was used to compute the nitrate reductase activity.

Procedure. Phosphate buffer with the molarity of 0.02 $\mathrm{M}$ was added in leaf sample. From this mixture $1 \mathrm{~mL}$ was taken out and $0.02 \mathrm{M} \mathrm{KNO}_{3}$ solution was entered in it. The amount of $\mathrm{KNO}_{3}$ used for this purpose was $1 \mathrm{~mL}$ and 1-naphthyl ethylene diamine dihydrochloride $(0.02 \%)$ was added in the solution after vigorous shaking of 1-naphthyl ethylene diamine dihydro-chloride. With $\mathrm{NO}_{2}$ diazocomplex, a pink colour was produced. Spectrophotometer was used to determine the absorbance at $542 \mathrm{~nm}$.

Total soluble sugars. Method proposed by Yemm and Willis (1954) was used to compute the total soluble sugars.

Procedure. In the test tubes of $25 \mathrm{~mL}$, plant extract $(0.3 \mathrm{~mL})$ was added. $6 \mathrm{~mL}$ of anthrone reagent was added in the test tubes. Then the test tubes were warmed in the boiling water bath for $10 \mathrm{~min}$. These test tubes were cooled down by placing them in chilled water for $10 \mathrm{~min}$ and then incubated for $20 \mathrm{~min}$ by maintaining the temperature at $25^{\circ} \mathrm{C}$. Spectrophotometer was used to measure the optical density at $625 \mathrm{~nm}$ (Hitatchi, 220, Japan). Standard curve was developed for the calculation of soluble sugars.

Na and $K$ analysis. Digestion. In the digestion tubes concentrated $\mathrm{H}_{2} \mathrm{SO}_{4}$ was added with $0.5 \mathrm{~g}$ of ground material (Wolf and Stahl, 1982). 35\% hydrogen peroxide was added in the digestion tubes. After this they were heated at $350{ }^{\circ} \mathrm{C}$ in the digestion block. This process of heating was continued for $30 \mathrm{~min} .0 .5 \mathrm{~mL}$ of hydrogen peroxide was added in it. For making the digested material colourless $0.5 \mathrm{~mL}$ hydrogen peroxide was added and the tubes were placed again in the digestion block. This step was done again and again until the solution became colourless. The volume was kept $50 \mathrm{~mL}$ in volumetric flasks by adding distilled water.

Estimation of cations $\left(\mathrm{Na}^{+}\right.$and $\left.\mathrm{K}^{+}\right)$. Method proposed by Jenway (PFP 7) was used to determine sodium $\left(\mathrm{Na}^{+}\right)$ and potassium $\left(\mathrm{K}^{+}\right)$with the help of flame photometer PFP7 (Yilmaz and Yavuz, 1999).

Calcium determination. Method proposed by salinity laboratory (Kunze and Dixon, 1986) was used to determine calcium.

Yield and yield components. Plant height was recorded using a meter rod. Data for yield and yield components were recorded at maturity.

Statistical analysis. Analysis of variance of the data from each attribute was computed using three factor factorial design (Steel et al., 1997).

\section{Results and Discussion}

As shown by Table 1 that salinity stress has significantly reduced the growth and production of brassica but the 
exogenous application of proline and glycine betaine minimizes the effect of salinity. Salinity has decreased plant height (Fig. 1), shoot fresh weight (Fig. 2), shoot dry weight (Fig. 3), root fresh weight (Fig. 4), root dry weight (Fig. 5), Chl a (Fig. 6), Chl b (Fig. 7), total Chl (Fig. 8), total soluble sugars (Fig. 9), protein (Fig. 10), total free amino acids (Fig. 11), NRA (Fig. 12), potassium (Fig. 13), calcium (Fig. 14) and sodium (Fig. 15) increased under salt stress. As shown that $8 \mathrm{mM}$ and $10 \mathrm{mM}$ concentration of proline and glycine betaine were more effective to reduce the effect of salinity as compared to $4 \mathrm{mM}$ and $5 \mathrm{mM}$ concentrations of proline and glycine betaine. Sodium ions present in the growth mediums showed antagonistic effect on calcium and potassium ions.

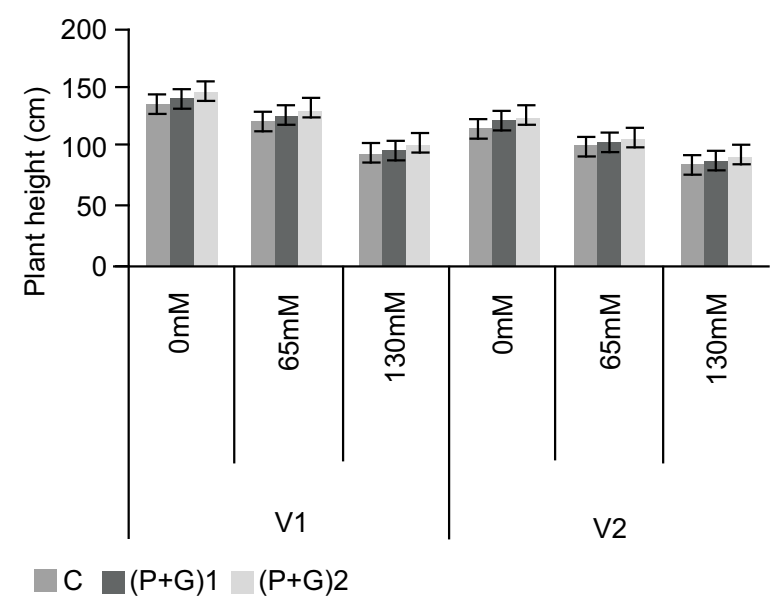

Fig. 1. Concentration of proline/glycine betaine.

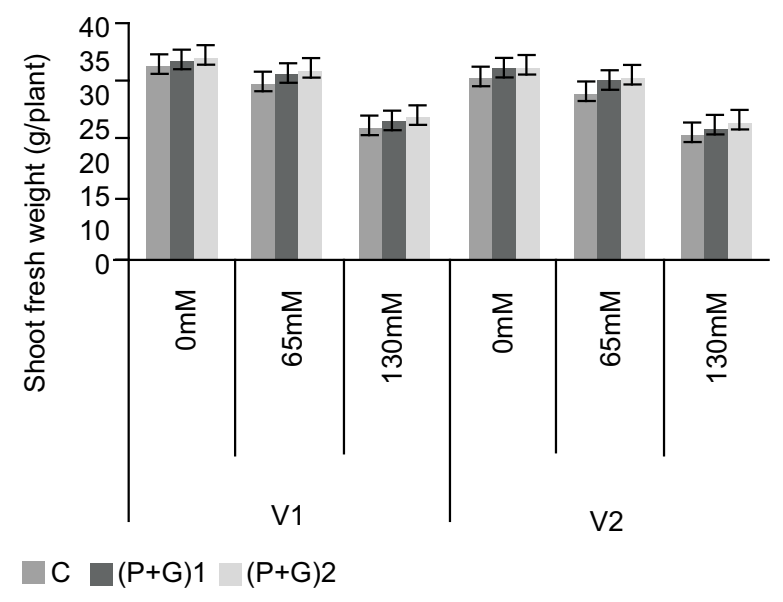

Fig. 2. Concentration of proline/glycine betaine.

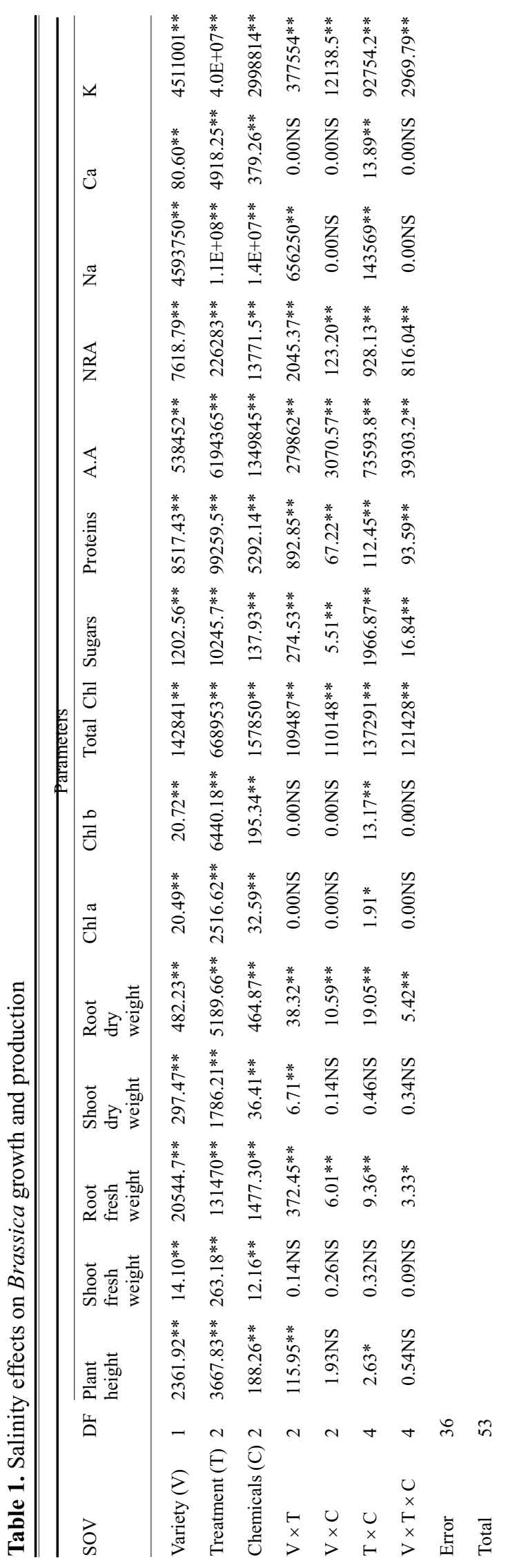




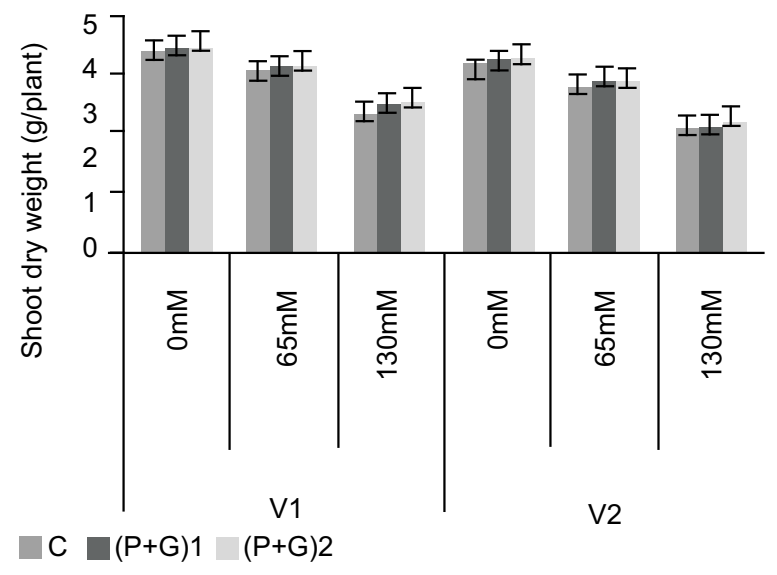

Fig. 3. Concentration of proline/glycine betaine.

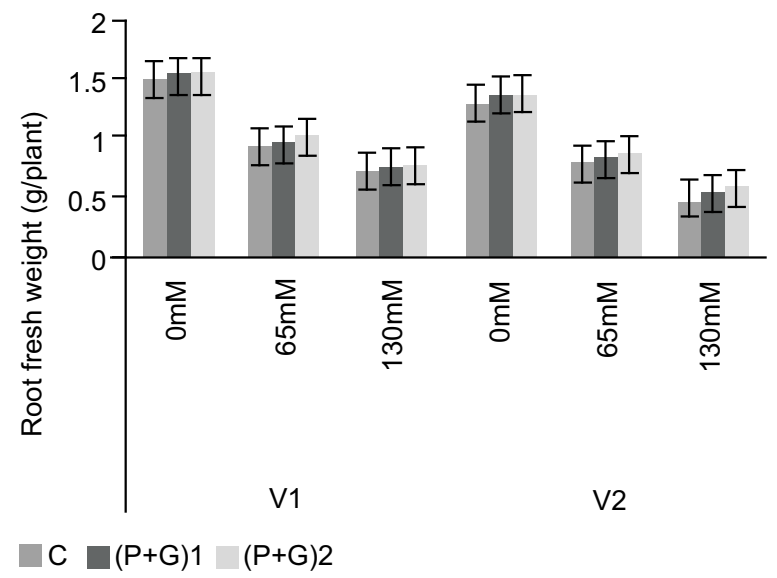

Fig. 4. Concentration of proline/glycine betaine.

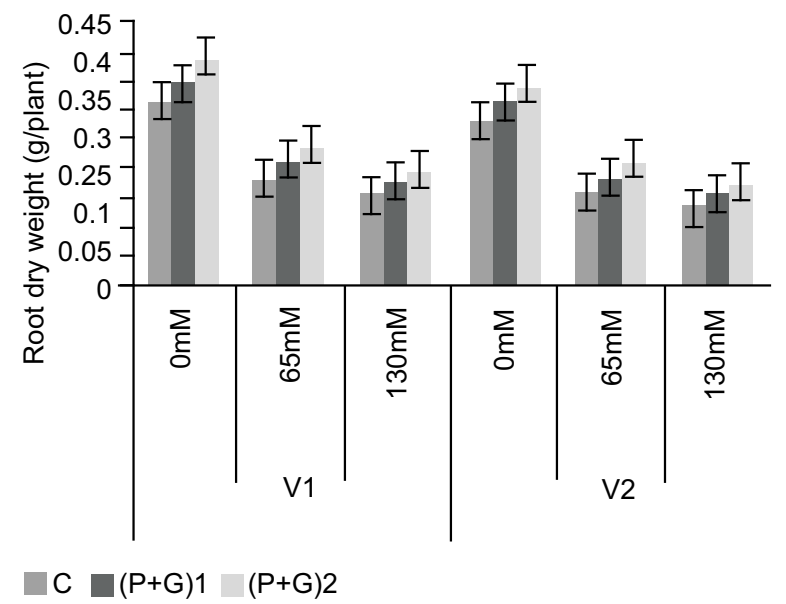

Fig. 5. Concentration of proline/glycine betaine.

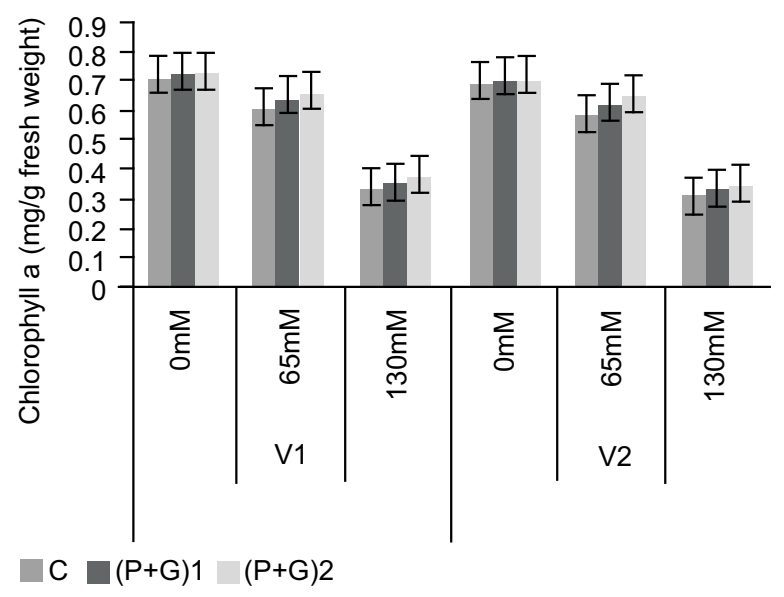

Fig. 6. Concentration of proline/glycine betaine.

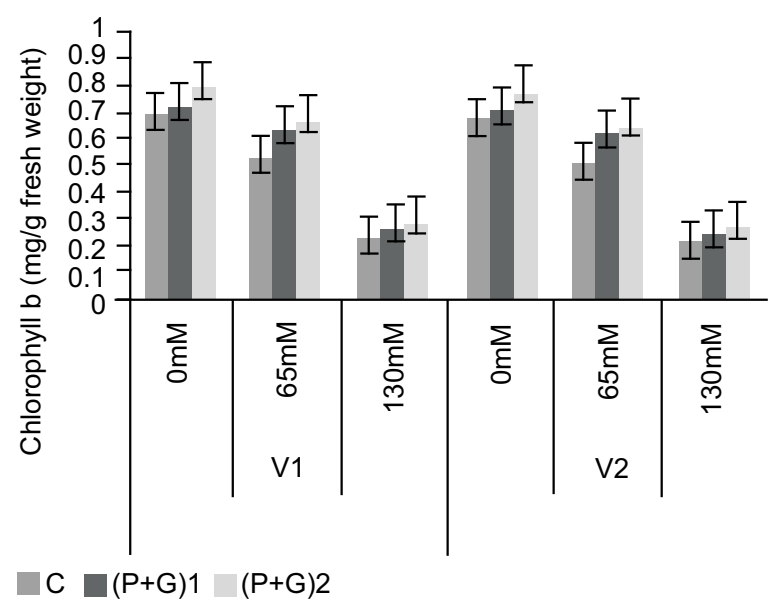

Fig. 7. Concentration of proline/glycine betaine.

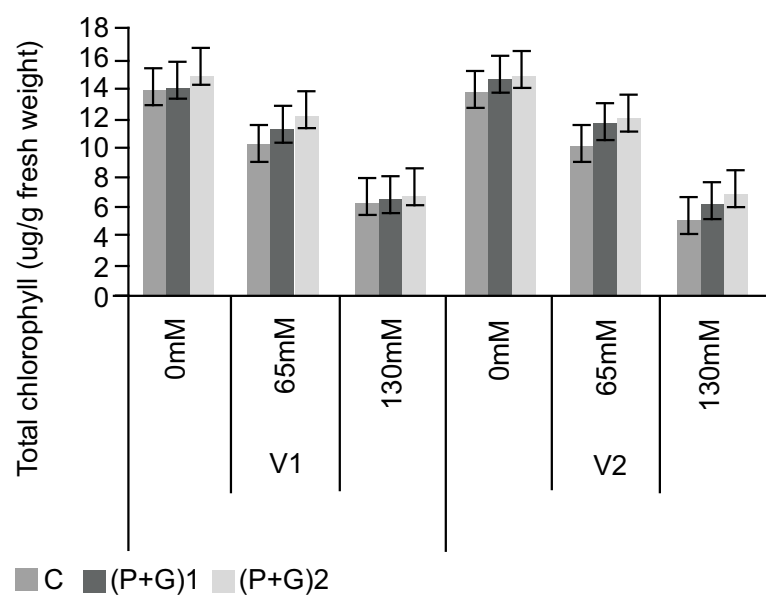

Fig. 8. Concentration of proline/glycine betaine. 


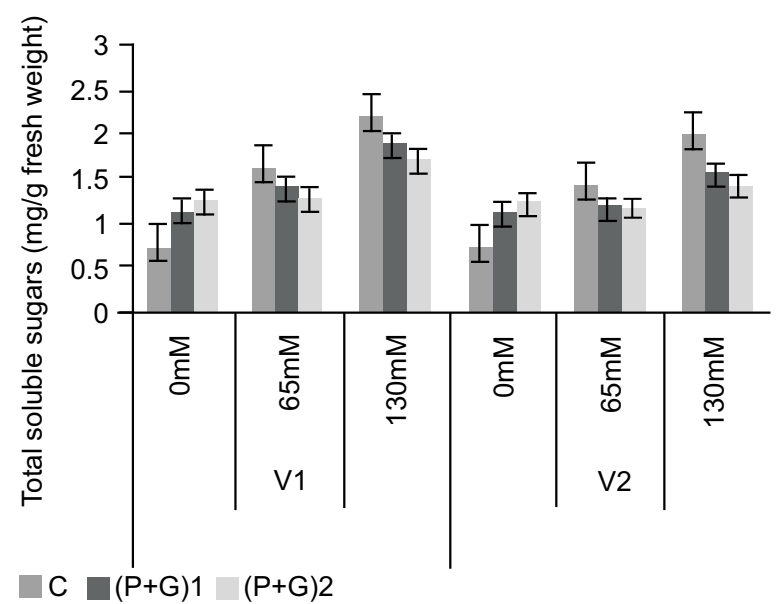

Fig. 9. Concentration of proline/glycine betaine.

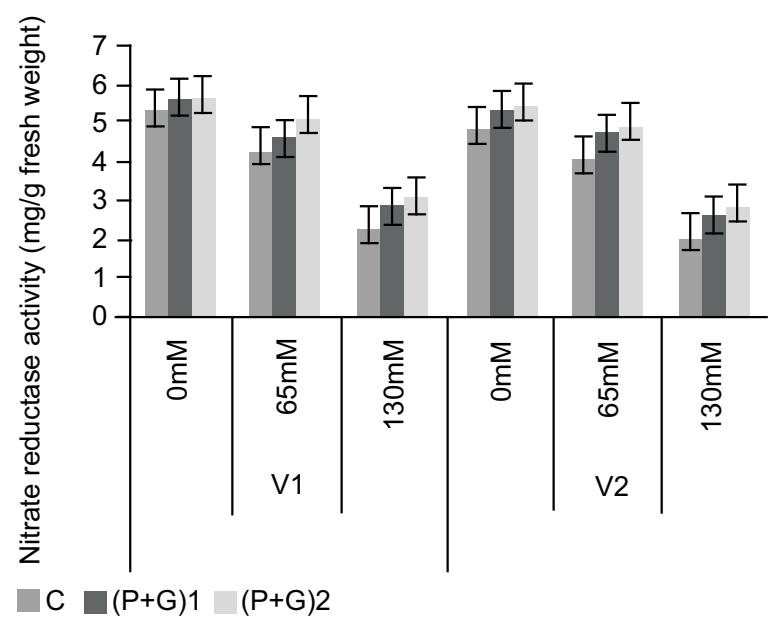

Fig. 12. Concentration of proline/glycine betaine.

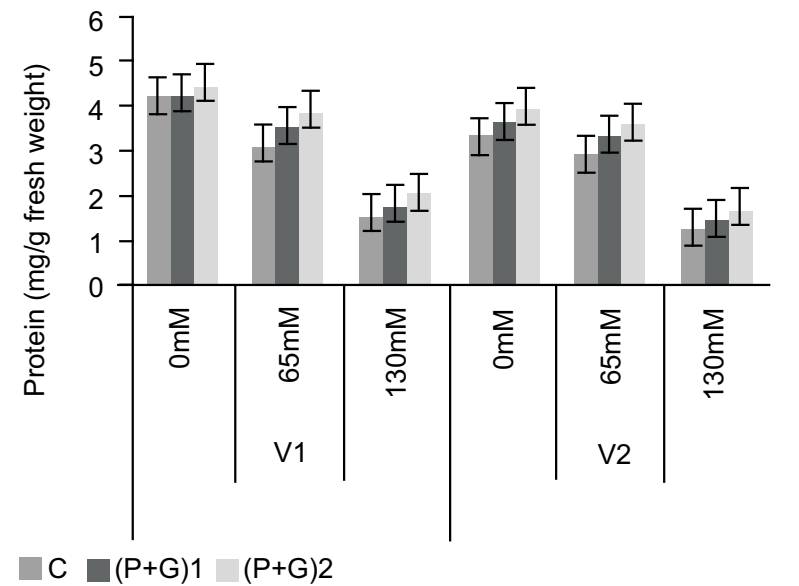

Fig. 10. Concentration of proline/glycine betaine.

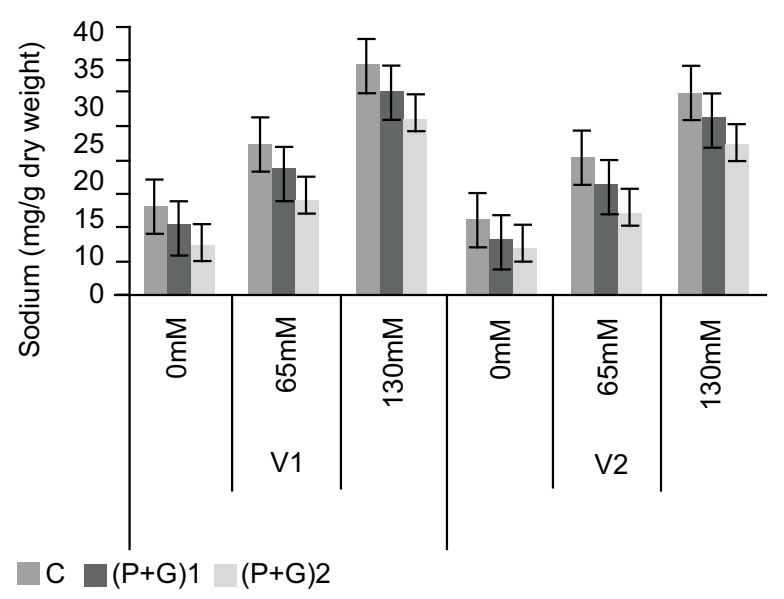

Fig. 13. Concentration of proline/glycine betaine.

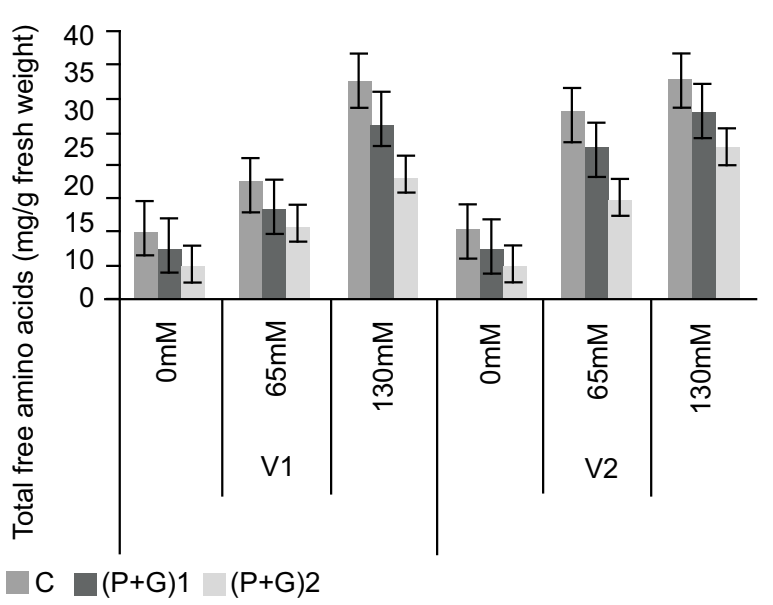

Fig. 11. Concentration of proline/glycine betaine.

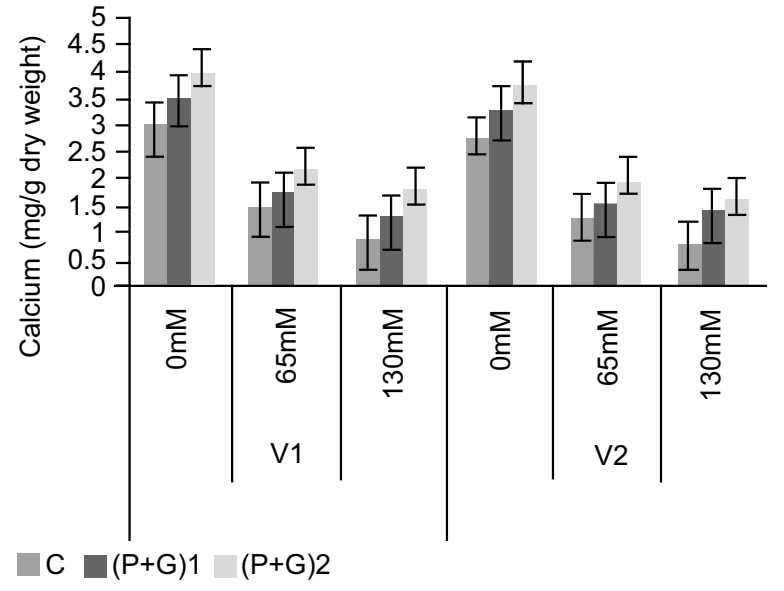

Fig. 14. Concentration of proline/glycine betaine. 


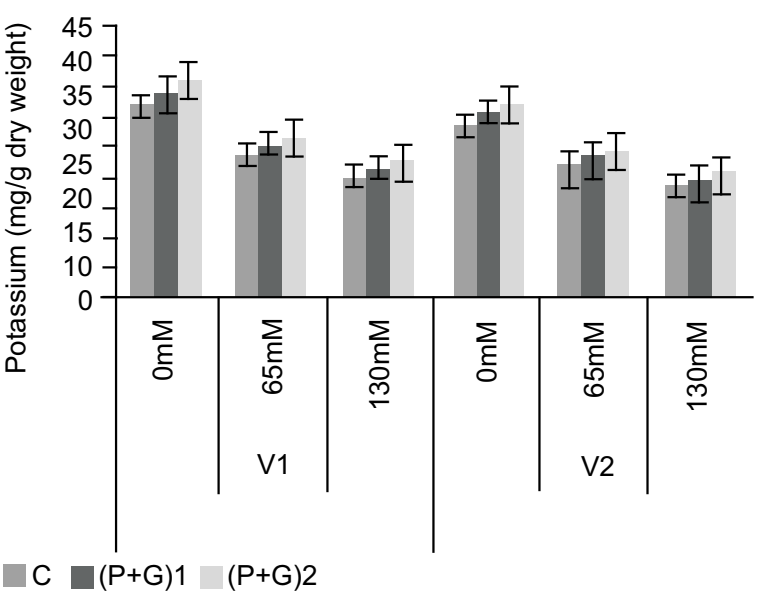

Fig. 15. Concentration of proline/glycine betaine.

Figure 1-15 shows the effect of exogenous application of proline and glycine betaine on plant height, shoot and root fresh and dry weight, shoot, $\mathrm{Chl} \mathrm{a}, \mathrm{Chl} \mathrm{b}$, total Chl, protein, total free amino acids, NRA, sodium, calcium, potassium of brassica under saline and nonsaline conditions.

Salinity tolerance in brassica increased by exogenous application of proline and Glycine betaine. Glycine betaine content was observed to be increased under salt stress (Amandeep et al., 2014).

Glycine betaine was found effective to decrease salt stress damage when it was exogenously applied on canola (Athar et al., 2015). With glycine betaine, proline also play role in improving plant growth. The application of 1 and $5 \mathrm{mM}$ proline improved the growth of brassica varieties (Posmyk and Janas, 2007). Salinity levels increases uptake of $\mathrm{Na}^{+}$in all plant parts including root, stem and leaf. Simultaneously it decreases the calcium and potassium uptake due to antagonistic effects. The addition of $\mathrm{Na}^{+}$in plant parts increased as the level of salinity was increased. The amount of proline, soluble carbohydrates and reduced sugar increased as salinity increased (Mostajeran and Gholaminejad, 2014).

Proline is a widespread compatible solute. There are many roles for proline in saving plants from harmful and damaging effects of salinity. It can stabilize the membranes and guard them from harmful ions which can destroy their structure (Khan et al., 2009). Proline and glycine betaine can be used to check the salt tolerance ability of different plant species (Ahmad et al., 2009).
Foliar spray of proline and glycine betaine enhances the development of both salt affected and non-stressed plants of canola varieties. Same results have been observed in maize (Nawaz and Ashraf, 2007) and wheat (Raza et al., 2007).

It is clear from the outcomes of current study that salinity stress reduced plant growth, plant height, dry biomass and fresh weight. Growth of all the plants increased by applications of proline and glycine betaine, either the plants were facing salinity or were grown under non saline conditions. $\mathrm{Chl} \mathrm{a}, \mathrm{Chl} \mathrm{b}$ and total chlorophyll were also reduced under salt stress but their value increased when proline and glycine betaine were applied on the plants. The 4 and $5 \mathrm{mM}$ levels of proline and glycine betaine are less effective to reduce salinity than 8 and $10 \mathrm{mM}$ levels of proline and glycine betaine. Proline and glycine betaine decreased the harmful effects of salinity stress and enhanced the growth of plants. The encouraging effects are clear from the above results.

\section{References}

Ahmad, P., Hakeem, K.R., Kumar, A., Ashraf, M., Akram, N.A. 2012. Salt induced changes in photosynthetic activity and oxidative defense system of three cultivars of mustard (Brassica juncea L.). African Journal of Biotechnology, 11: 2694-2703.

Ahmad, P., Jeleel, C.A., Azooz, M.M., Nabi, G. 2009. Generation of ROS and non-enzymatic antioxidants during abiotic stress in plants. Botany Research International, 2: 11-20.

Ali, Q., Ashraf, M. 2011. Induction of drought tolerance in maize (Zea mays L.) due to exogenous application of trehalose: growth, photosynthesis, water relations and oxidative defence mechanism. Journal of Agronomy Crop Science, 197: 258-271.

Amandeep, R., Kapoor, N., Bhardwaj, R. 2014. Role of Brassinosteroids in osmolytes accumulation under salinity stress in Zea mays plants. International Journal of Science and Research, 3: 23197064.

Anjum, S.A., Farooq, M., Xie, X., Liu, X.J., Ijaz, M.F. 2012. Antioxidant defense system and proline accumulation enables hot pepper to perform better under drought. Scientia Horticulturae, 140: 66-73.

Ashraf, M., Foolad, M.R. 2007. Roles of glycine betaine and proline in improving plant abiotic stress resistance. Environmental and Experimental Botany, 59: 206-216.

Athar, H.U.R., Zafar, Z.U., Ashraf, M. 2015. Glycine 
betaine Improved photosynthesis in canola under salt stress: evaluation of chlorophyll fluorescence parameters as potential indicators. Journal of Agronomy and Crop Science, 201: 428-442.

Aymen, E.M., Cherif, H. 2013. Influence of seed priming on emergence and growth of coriander (Coriandrum sativum L.) seedlings grown under salt stress. Acta Agricultural Slovent, 101: 41-47.

Chambo, E.D., Oliveira, N.T.D., Garcia, R.C., DuarteJunior, J.B., Ruvolo-Takasusuki, M.C.C., Toledo, V.A. 2014. Pollination of rapeseed (Brassica napus) by Africanized honeybees (Hymenoptera: Apidae) on two sowing dates. Anais da Academia Brasileira de Ciências, 86: 2087-2100.

Chaum, S., Singh, H.P., Samphumphuang, T., Kirdmanee, C. 2012. Calcium-alleviated salt tolerance in indica rice (Oryza sativa L. spp. indica): physiological and morphological changes. Austratian Journal of Crop Sciences, 6: 176-182.

Chelli-Chaabounia, A., Mosbahb, A.B., Maalej, M., Gargouric, K., Gargouri-Bouzidd, R., Drira, N. 2010. In vitro salinity tolerance of two pistachio rootstocks: Pistacia vera L. and P. atlantica Desf. Environmental and Experimental Botany, 69: 302-312.

Cominelli, E., Conti, L., Tonelli, C., Galbiati, M. 2013. Challenges and perspectives to improve crop drought and salinity tolerance. New Biotechnology Journal, 8: 355-361.

Davies, B.H. 1976. Chemistry and Biochemistry of Plant Pigments. T. W. Goodwin (eds.), vol. 2, pp. $38-165,2^{\text {nd }}$ edition, Academic Press, London, UK.

Gilberti, S., Funck, D., Forlani, G. 2014. D1-pyrroline5-carboxylate reductase from Arabidopsis thaliana: stimulation or inhibition by chloride ions and feedback regulation by proline depend on whether NADPH or NADH acts as co-substrate. New Phytologist, 202: 911-919.

Hamilton, P.B., VanSlyke, D.D. 1943. Amino acid determination with ninhydrin. Journal of Biological Chemistry, 150: 231-233.

Hoque, M.A., Banu, M.N.A., Okuma, E., Amako, K., Nakamura, K., Shimoishi, Y., Murata, Y. 2007. Exogenous proline and glycinebetaine increase $\mathrm{NaCl}$ induced ascorbate glutathione cycle enzyme activities and proline improves salt tolerance more than glycinebetaine in tobacco bright yellow 2 suspension cultured cells. Journal of Plant Physiology,
164: 1457-1468.

Kapoor, R., Evelin, H., Mathur, P., Giri, B. 2013. Arbuscular mycorrhiza Approaches for Abiotic Stress Tolerance in Crop Plants for Sustainable Agriculture. In: Plant Acclimation to Environmental Stress, N. Tuteja and S. S. Gill (eds.), pp. 359-401, Springer, New York, USA.

Khan, M.A., Shirazi, M.U., Khan, M.A., Mujtaba, S.M., Islam, E., Mumtaz, S., Shereen, A., Ansari, R.U., Ashraf, M.Y. 2009. Role of proline, K/Na ratio and chlorophyll content in salt tolerance of wheat (Triticum aestivum L.). Pakistan Journal of Botany, 41: 633-638.

Kunze, G.W., Dixon, J. 1986. Pretreatment for mineralogical analysis. Methods of Soil Analysis: Part-1, $2^{\text {nd }}$ edition, Physical and Mineralogical Methods, pp. 91-100, American Society of Agronomy, Wisconsin, USA.

Latef, A.A.H.A., Chaoxing, H. 2014. Does the inoculation with Glomus mosseae improve salt tolerance in pepper plants. Journal of Plant Growth Regulation, 33: 644-653.

Mostajeran, A., Gholaminejad, A. 2014. Effect of salinity on sodium and potassium uptake and proline, carbohydrates contents of turmeric plant parts. Journal of Current Chemical and Pharmaceutical Sciences, 4: 10-21.

Muhammad, S., Muhammad, T.S. 2007. Comparative use of organic substrates and mineral fertilizers in growing maize (Zea mays L.) for maintaining soil fertility in rainfed area of Pakistan. Pakistan Journal of Botany, 39: 1953-1959.

Nawaz, K., Ashraf, M. 2007. Improvement in salt tolerance of maize by exogenous application of glycinebetaine: growth and water relations. Pakistan Journal of Botany, 39: 1647-1653.

Posmyk, M.M., Janas, K.M. 2007. Effects of seed hydropriming in presence of exogenous proline on chilling injury limitation in Vigna radiata L. seedlings. Acta Physiologiae Plantarum, 29: 509517.

Raza, S.H., Athar, H.R., Ashraf, M., Hameed, A. 2007. GB-induced modulation of antioxidant enzymes activities and ion accumulation in two wheat cultivars differing in salt tolerance. Environmental and Experimental Botany, 60: 368-378.

Snowdon, R., Luhs, W., Friedt, W. 2007. Oil seed rape. Oil Seeds, pp. 55-114, Springer Berlin Heidelberg, Germany. 
Steel, R.G.D., Torrie, J.H., Dickey, D.A. 1997. Principles and Procedures of Statistics. A Biometrical Approach, 666 pp., $3^{\text {rd }}$ edition, McGraw Hill Book Co., New York, USA.

Sym, G.J. 1984. Optimization of the in vivo assay condition for nitrate reductase in barley. Journal of the Science of Food and Agriculture, 35: 550-556.

Taie, H., Abdelhamid, M.T., Dawood, M.G., Nassar, R.M. 2013. Presowing seed treatment with proline improves some physiological, biochemical and anatomical attributes of faba bean plants under sea water stress. Journal of Applied Sciences, 9: 28532867.

Wolf, B., Stahl, O. 1982. AG CAR-A Galactic S DOR variable. Astronomy and Astrophysics, 112: 111115

Yimm, E.W., Willis, A.J. 1954. The estimation of carbohydrates in plant extracts by anthrone. Biochemical Journal, 57: 508-514.

Yilmaz, H., Yavuz, O. 1999. Content of some trace metals in honey from south-eastern Anatolia. Food Chemistry, 65: 475-476. 